Journal of the

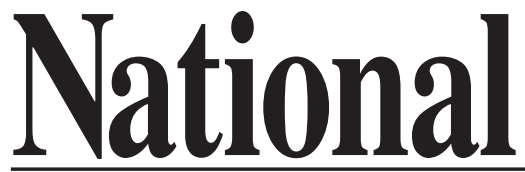

Academy or

Forensic
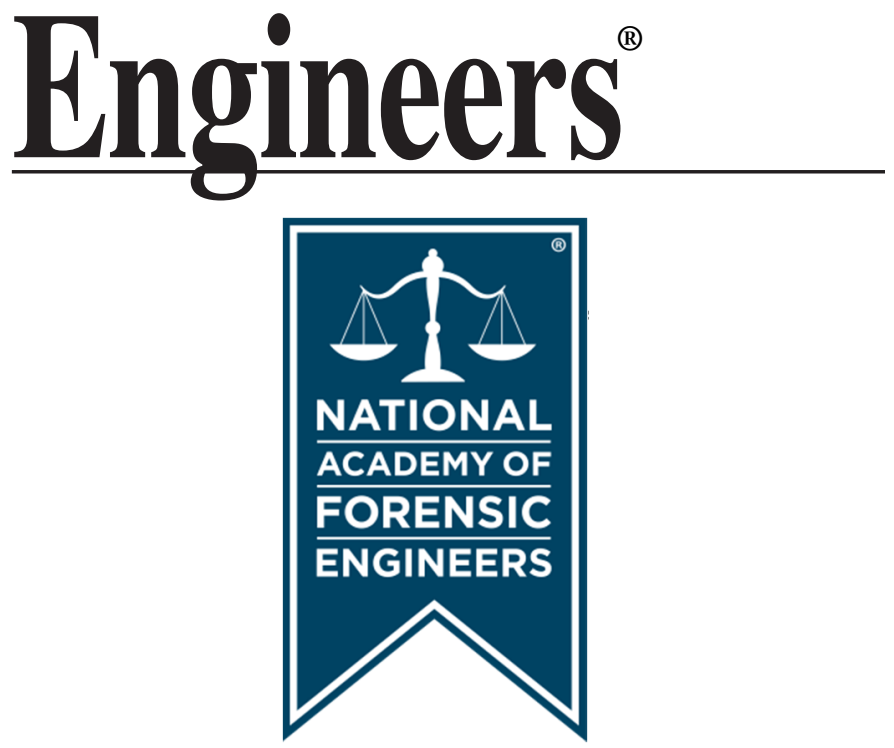

http://www.nafe.org ISSN: 2379-3252 


\title{
Forensic Engineering \\ Use of Walkway Traction Testing
}

by John Leffler, P.E. (NAFE 709M)

\begin{abstract}
Pedestrian fall events are frequently linked to "slippery" walkway surfaces. Friction is the measured quantity at issue in traction testing which has been conducted using various devices for over 80 years. The various available devices (called "tribometers") each have their advocates, resulting in a certain amount of controversy. Robust analysis of walkway traction requires an understanding of individual tribometer characteristics and knowledge of potential limitations in the ability to test certain surfaces \& contaminants. It is also necessary to understand the status of relevant traction testing standards and to be familiar with current research which links tribometer and human subject testing to provide required friction values for safe pedestrian ambulation.
\end{abstract}

\section{Keywords}

Forensic engineer, slip, fall, tribometer, traction, slope, ramp, friction, bathtub

\section{Introduction}

There are three general types of slip events:

\section{Heel strike}

A heel strike slip is the most common cause of a slip-related fall. During the stride, as the leading heel contacts the walkway, the heel slides forward. The forward momentum of the pedestrian exacerbates the slip, and the leading leg can no longer support its share of the body weight.

\section{Toe-off}

A toe-off slip occurs when the trailing foot slips as the toes push off. A toeoff slip rarely results in a fall, since the majority of body weight will already have been shifted to the leading leg.

\section{Fore-aft split}

The elderly are the most susceptible to a fore-aft split slip event. In these slip events, the lower extremities are not strong enough to keep from spreading apart into an increasingly longer stride, and a fall to the side is typical. 
Copyright $\odot$ National Academy of Forensic Engineers (NAFE) http://www.nafe.org. Redistribution or resale is illegal.

Originally published in the Journal of the NAFE volume indicated on the cover page. ISSN: 2379-3252

These types of falls can be caused by a walkway surface that lacks sufficient traction for that particular coupling of pedestrian and footwear, given the contaminants and other extrinsic factors that may be present. Analysis of pedestrian traction involves the empirical study of friction, the factor that complicates most interactions of adjacent objects in contact. Due to the variables of adjacent surface roughness, slope, contours, contact force, hysteresis, mechanical \& molecular bonding, deformation, wear, contaminants, and other factors, every measurement of friction will be slightly different. Effective measurement of pedestrian traction involves tribometers that attempt to consistently accommodate (if not eliminate) the effects of these variables. As a result, it is not reasonably possible (because of these variables) to objectively quantify pedestrian traction through "informal" methods such as a visual inspection, scuffing one's shoes on the surface, or rubbing the surface with fingertips. Tribometers are necessary for meaningful analysis.

Tribometers produce a measurement or reading. That measurement is commonly used in pronouncing the walkway "safe" or "unsafe" or "slippery" or "slip resistant", or similar. However, any measurement is meaningless without an established reference. Similarly, there must be a robust basis for linking the tribometer measurements to the actual potential for a pedestrian slip. Therefore, a reliable tribometer would measure as "slippery" only those surfaces objectively found "slippery" by humans.

\section{Pedestrian traction testing terms}

Traction testing is a term that encompasses both coefficient-of-friction testing and slip resistance testing.

\section{Coefficient of friction}

Many types of tribometers claim to measure the coefficient of friction, abbreviated COF. The maximum COF between two surfaces will typically be at the threshold of movement. For static coefficient of friction (SCOF), the maximum value will be just at the point of incipient relative movement, and for dynamic coefficient of friction (DCOF), the maximum value will typically be when the moving surface has minimal velocity. As COF is between two surfaces, testing of wet or contaminated walkway surfaces traditionally is not called coefficient of friction testing, it is slip resistance testing.

\section{Slip resistance}

The term "slip resistance" is defined in ASTM F1646 ${ }^{1}$ as

"The relative force that resists the tendency of the shoe or foot to slide along the walkway surface. Slip resistance is related to a combination of factors 
Copyright $\odot$ National Academy of Forensic Engineers (NAFE) http://www.nafe.org. Redistribution or resale is illegal.

Originally published in the Journal of the NAFE volume indicated on the cover page. ISSN: 2379-3252

including the walkway surface, the footwear bottom, and the presence of foreign materials between them."

Additional discussion in that F1646 terminology standard includes reference to the capabilities of the pedestrian and other factors. As such, it is clear that slip resistance is not the same as coefficient of friction, though the terms are frequently used interchangeably. It is important to note, however, that a tribometer is a mechanical device, and as such cannot tangibly account for individual pedestrian gait peculiarities or other intrinsic factors.

\section{Overview of standards and laws}

There is a popular understanding that a value of 0.5 is the "threshold" for adequate traction on a walkway. This 0.5 value has been commonly referenced for over 60 years - despite the lack of a reliable scientific foundation, and despite constant evolution in test methods and research.

In the United States, there are several standards development organizations that offer standards related to pedestrian safety. As reference, ANSI is the American National Standards Institute, which accredits standards development organizations.

- ASTM International (formerly American Society of Testing and Materials)

- F13: Pedestrian Walkway Safety \& Traction

- F15.03: Safety Standards for Bathtub and Shower Structures

- ANSI / American Society of Safety Engineers (ASSE)

- A1264.2 Subgroup: Standards for Slip Resistance and Prevention of Slips, Trips and Falls

- ANSI / National Floor Safety Institute (NFSI)

- B101: Committee on Slip, Trip and Fall Prevention

- ANSI / International Code Commission (ICC)

- A117: Architectural Features and Site Design of Public Buildings and Residential Structures for Persons with Disabilities

The latter committee above, A117, administers the A117. $1^{2}$ standard that formed the basis for the Americans with Disabilities Act standards for walkways. Many Occupational Safety and Health Administration (OSHA) regulations generically require "slip resistant" walkways, but the more specific Federal laws that pertain to walkways are established by:

- 28CFR36 Americans With Disabilities Act

- Appendix A: ADA Standards for Accessible Design 
Copyright $\odot$ National Academy of Forensic Engineers (NAFE) http://www.nafe.org. Redistribution or resale is illegal

Originally published in the Journal of the NAFE volume indicated on the cover page. ISSN: 2379-3252

- United Stated Department of Labor - OSHA

- Notice of Proposed Rulemaking, Federal Register 68:23527-23568 Walking and Working Surfaces; Personal Protective Equipment (Fall Protection Systems

However, despite the history of reference to the 0.5 value, there are at this time no common standards or laws that establish 0.5 (or any other value) as the minimum required COF or slip resistance value for a walkway. Laws and standards from the above entities only describe specific values for traction in advisory and non-mandatory sections. As measurements are meaningless without an established reference, codification of a "target" minimum traction would require agreements on what tribometer and methodology to use for testing and what reference surface(s) to use for baseline values - and there currently are no such agreements. As will be discussed, recent research may provide future opportunities to establish specific and reliable threshold values - and the anecdotal 0.5 value may lose its popularity.

\section{Common tribometers and US standards}

The tribometers described below are common in the United States. These devices are portable and capable of field testing. The tribometer contacts the walkway surface with a "testfoot". Most tribometers use a laboratory-grade standardized rubber called Neolite for their testfoot material; some tribometers still use leather despite leather's inconsistency (being an organic material). There are many other designs of traction testing devices in use around the world.

\section{Dragsleds}

Dragsleds involve dragging a testfoot across the walkway surface of interest. As discussed above, the peak value for COF will be at the thresholds of motion, and in operation the testfoot will be brought to the point of sticking to / slipping on the walkway surface. This stick-slip phenomenon of adhesion (also called "sticktion") has been known for decades ${ }^{3}$ to affect accuracy of measurement, due to the bonding of the testfoot to the walkway surface while stationary. Adhesion is particularly problematic in wet surface testing; such bonding results in artificially high measurement values - walkways will test as being "safer" then they may actually be.

- Horizontal Dynamometer Pull-Meter: This device is described in ASTM C1028- $07^{4}$, and is still referenced for COF testing of floor finishes and ceramic tile. It is hand-pulled along the walkway surface, and it is an assembly of a digital force gauge, a thick aluminum plate with Neolite pads glued to the underside, and a 50 pound weight.

- RSI BOT 3000: This device ${ }^{5}$ is a motorized dragsled, descended from the 
Copyright @ National Academy of Forensic Engineers (NAFE) http://www.nafe.org. Redistribution or resale is illegal Originally published in the Journal of the NAFE volume indicated on the cover page. ISSN: 2379-3252

earlier Universal Walkway Tester. This is the only tribometer currently approved for use with a recent standard, ANSI/NFSI B101.1 ${ }^{6}$. The device's instructions describe using a leather testfoot for dry COF testing and a Neolite testfoot for wet COF testing. Also per the operating instructions, this tribometer travels along the walkway surface approximately $6-15$ inches, and it must be used on level surfaces.

- ASM 825: This device ${ }^{7}$ (formerly the ASM 725) contains electronics but is hand-pulled across the surface by the user. It uses three small Neolite discs as testfeet.

\section{Articulated-strut tribometers}

Tribometers of this type apply loads to an angled strut which "kicks out" when a slip occurs. All but the first of the mentioned designs avoid adhesion by applying the horizontal and vertical components of the test load to the testfoot simultaneously.

- NIST-Brungraber Mark I Portable Articulated Strut Tribometer (PAST): This device was the first popular portable walkway tester in the US, and was designed in the mid-1970s by Robert Brungraber, $\mathrm{PhD}, \mathrm{PE}$ under a grant from the National Bureau of Standards (now the National Institute of Standards and Technology). This device operates by first resting the testfoot on the walkway surface, making it susceptible to adhesion. This tribometer was referenced by the now-withdrawn ASTM F1678- $96^{8}$ standard, where it was recommended for dry testing. See Figure 1.

Though no longer manufactured, this tribometer is currently used for the ASTM F462-79 (reaffirmed in 2007) bathing surfaces test $^{9}$. In this method, it uses a cast silicone rubber testfoot, which rests in a pool of soapy water on the test surface prior to actuation. This test will be discussed in more detail later.

- Brungraber Mark II Portable Inclinable Articulated Strut Slip

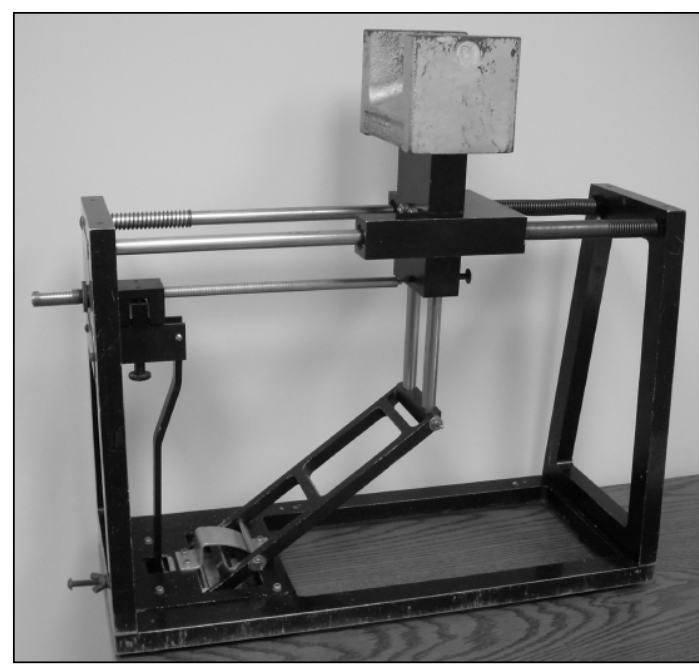

Figure 1

NIST-Brungraber Mark I tribometer 
Copyright $\odot$ National Academy of Forensic Engineers (NAFE) http://www.nafe.org. Redistribution or resale is illegal. Originally published in the Journal of the NAFE volume indicated on the cover page. ISSN: 2379-3252

Tester (PIAST): This device ${ }^{10}$ is referenced in ASTM F1677-05 ${ }^{11}$, which was withdrawn in 2006 due to its reference to a proprietary device (not allowed by ASTM) and lack of a published precision \& bias statement (required by ASTM). The tribometer uses a sliding 10 pound weight for actuation of its testfoot. See Figure 2.

Though this tribometer is capable of testing on slopes, the 10 pound weight can affect readings on slopes or at high slip angle values. The typical testfoot material is Neolite, and current practice is to groove the Neolite $^{12}$ in order to avoid hydroplaning of the testfoot in wet slip resistance testing of smooth surfaces.

- English XL Variable Incidence Tribometer: This device ${ }^{13}$ is referenced in ASTM F1679$04^{14}$, which was also withdrawn in 2006 due to its reference to a proprietary device and lack of a precision \& bias statement. See Figure 3.

The device uses a pressurized $\mathrm{CO} 2$ cylinder for manually-triggered pneumatic actuation of its Neolite testfoot. This tribometer can be used on slopes.

- Brungraber Mark III Portable Inclinable Articulated Strut Slip

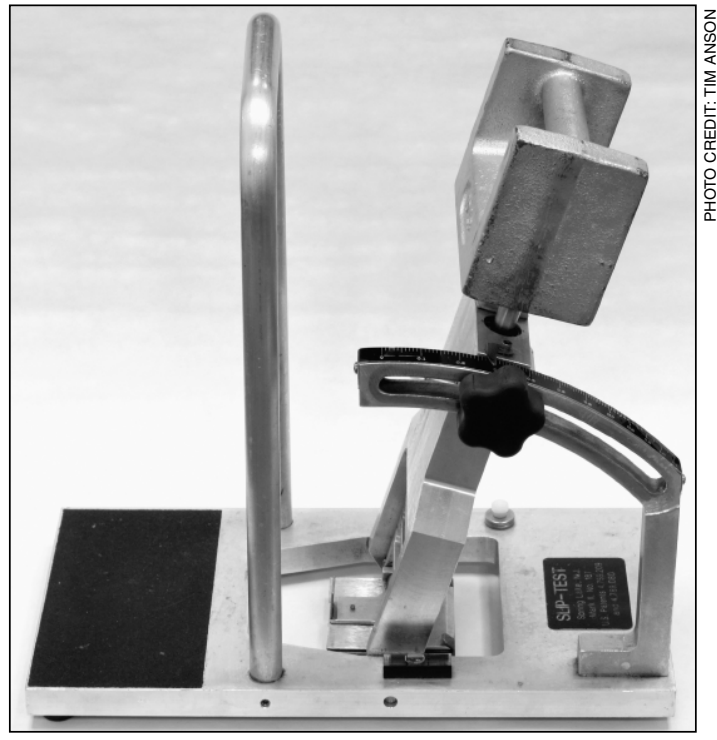

Figure 2

Brungraber Mark II tribometer

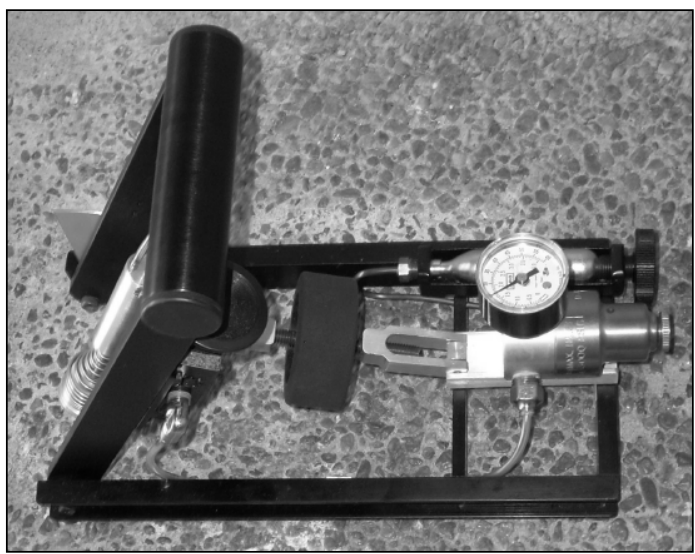

Figure 3

English XL tribometer 
Copyright @ National Academy of Forensic Engineers (NAFE) http://www.nafe.org. Redistribution or resale is illegal. Originally published in the Journal of the NAFE volume indicated on the cover page. ISSN: 2379-3252

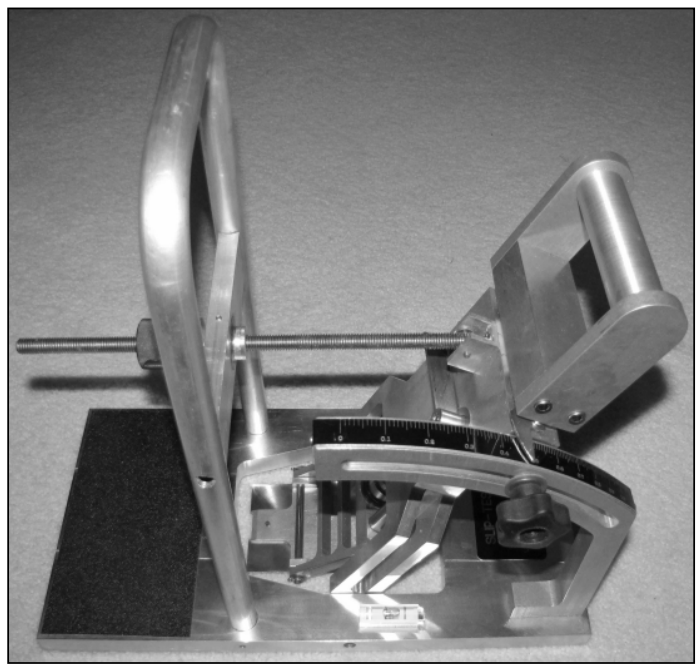

Figure 4

Brungraber Mark III tribometer
Tester (PIAST): This device ${ }^{15}$ is basically a spring-actuated version of the Mark II PIAST described above, eliminating the Mark II's 10 pound weight. See Figure 4.

There have been no published standards for Mark III use, though it is referenced in ASSE TRA $1264.3-07^{16}$ and is compared to the Mark II in several studies, including Powers ${ }^{17}$ and Li (2009). This tribometer can be used on slopes.

Of interest is the relationship between two widely-known traction requirements: the ADA \& ICC A117.1 (non-mandatory) requirements for walkways and ramps, and the ASTM F462 bathtub test. The research leading to both of these requirements was conducted with a Brungraber Mark I tribometer. As mentioned, the F462 bathtub test is conducted using a cast silicone rubber testfoot material; this was intended to simulate human skin. Apparently the same silicone rubber testfoot material was used for the research leading to the ADA/ICC A117.1 requirements of $0.6 \mathrm{COF}$ for walkways and $0.8 \mathrm{COF}$ for ramps ${ }^{18}$. In essence, a soft and adherent testfoot material meant to simulate skin was used for walkway testing intended to correlate to pedestrians wearing footwear.

As can be observed, there is a varied history of individual tribometer standards, some of which have been withdrawn - some which perhaps should be withdrawn. It is important to note, however, that there may be many reasons why a standard is withdrawn, and the existence of an active standard is not mandatory in order for a tribometer to provide meaningful data. Tribometer operation is only one part of a robust, defensible walkway analysis, and experts must be able to defend their choice of a particular tribometer and methodology, whether or not there is an active standard.

\section{Walking surfaces}

Actual walkway surfaces may be manufactured, fabricated onsite, or natural. Manufactured surfaces include ceramic tiles, vinyl composite tiles and rolls, concrete paving blocks, bricks, prefinished wood boards, and decking made of 
Copyright @ National Academy of Forensic Engineers (NAFE) http://www.nafe.org. Redistribution or resale is illegal.

Originally published in the Journal of the NAFE volume indicated on the cover page. ISSN: 2379-3252

molded plastic/sawdust. Fabricated surfaces include sanded wood boards, concrete, asphalt, and pourable polymers. Natural materials include slate, stone, rock, and gravel. Nearly all of these surfaces can receive an additional finish, such as a stain, varnish, oil, paint, sealer, polish, wax, appliqué, or tractioning additive. Some substrate/finish walkways are designed as a system, and in other cases finishes are applied independently to a pre-existing substrate.

One general way to characterize walkway surfaces is by their surface roughness and by the distribution of individual asperities. Surface roughness is the average height of the microscopic features and irregularities of the walkway surface. Asperities are the individual microscopic features that protrude above the basic "average" surface. Field measurement of surface roughness does not provide the best method for predicting pedestrian traction, as the height and sharpness of asperities may not be captured in the averaged values that are output from typical profilometers ${ }^{19}$. Contaminants (and finishes) will fill in surface roughness "low spots", and the individual asperities may remain as the microscopic features that provide mechanical grip. Also affecting mechanical grip is the compliance of the walkway and footwear surfaces. Molecular bonding is more prevalent with smooth walkway surfaces and smooth footwear soles, when fewer asperities are present. Chang ${ }^{20}$ provides more information.

- Issues regarding manufactured walkway surfaces

- Walkway surface manufacturers may advertise a certain level of traction for their product. For example, the previously-described ASTM C1028 test method, utilizing a 50-pound dragsled, is referenced by tile manufacturers and documents a certain coefficient of friction. However, the relevance (to pedestrian falls) of the reported COF values must be considered in the context of the testing method, the device used, and relevant fall incident data regarding the tested surface.

- Many ceramic tiles and paving blocks have significant designed-in surface contours meant to impart the "natural" variability of slate, rock, and stone. See the discussion of contoured surfaces below.

- Issues regarding fabricated-onsite walkway surfaces

- With these surfaces, the surface roughness, asperity shape, and asperity distribution will differ with every installation. In some cases, the surface roughness can be varied during fabrication, such as through "floating" or "broom finishing" of concrete. The ability to rely (for traction) upon consistency in the fabricated-onsite surface roughness and distribution of asperities, however, depends upon the repeatability of the process used to create that surface - for example, there is no standardization in broom finishes for concrete. As such, inconsistency in traction tester measurements may be expectable, both from the standpoint of an uneven pattern 
Copyright () National Academy of Forensic Engineers (NAFE) http://www.nafe.org. Redistribution or resale is illegal.

Originally published in the Journal of the NAFE volume indicated on the cover page. ISSN: 2379-3252

of roughness/asperities contacting the testfoot, and from the standpoint of an uneven distribution of roughness/asperities across the entire area of interest on the walkway.

- Many fabricated-onsite walkway surfaces end up with significant contours, either intentionally or unintentionally. See the discussion of contoured surfaces below.

- Issues regarding natural materials

- Slate, rock, stone, and gravel have a natural appearance which is often desirable. However, the first three may have surfaces with minimal surface roughness and asperities, and may provide inadequate traction. Natural slate tiles and rocks often have significant contours which affect tribometer testing, as discussed below.

- Issues regarding tribometer testing of significantly contoured surfaces

- As a tribometer testfoot is typically a thin polymer layer rigidly mounted to a metal backing plate, that testfoot won't be able to conform to significant contours in the same manner as would the sole of a normal shoe. As such, large portions of the testfoot surface area may not even contact the contoured walkway surface in testing, reducing the reliability of the test results.

- Significant contours serve as localized "ramps", uphill or downhill, that affect the ability of the testfoot to slip, depending upon the orientation of the tribometer relative to the contour and the contact position of the testfoot atop the contour. As the exact orientation and position of a pedestrian's heel contact on a walkway contour is typically unknown, significantly contoured walkway surfaces may not be capable of being reliably tested in connection with a particular alleged fall.

- Issues regarding finishes

- The majority of finishes applied to a walkway substrate are comprised of various types and proportions of solids, along with a liquid carrier or solvent that evaporates. Solids will serve to fill in the pores and low spots in the surface roughness, potentially reducing traction. Depending upon the volumetric proportion of solids, the viscosity of the finish, capillary action, the absorbency of the substrate, applied thickness, and other factors, the finish may significantly "blunt" the substrate asperities as well as fill in the low spots. Conversely, some finishes will serve to etch the substrate, "raise the grain" of wood flooring, or provide other potential enhancements to slip resistance.

- In addition to the mechanical effects of finish solids, these solids may have lubricating qualities, adherent qualities, or may affect the ability of the walkway to shed or absorb water (or contaminants). Manufacturer 
Copyright $\odot$ National Academy of Forensic Engineers (NAFE) http://www.nafe.org. Redistribution or resale is illegal.

Originally published in the Journal of the NAFE volume indicated on the cover page. ISSN: 2379-3252

instructions and MSDS sheets may provide information about the composition of the finish and its effect on traction. Some finishes reportedly comply with traction testing standards ${ }^{21}$, but as above the reported COF values should be considered in the context of the testing method, the device used, and available fall incident data regarding the tested finish.

- Finish durability varies; thinner or softer finishes may wear through or wear away relatively quickly, causing the surface roughness and asperities of the underlying substrate to provide more of the available traction. Similarly, a finish may have its own micro-roughness and asperities that will wear down over time, potentially reducing traction.

- Abrasive additives may be mixed in with some types of coatings. The effectiveness of these abrasives in enhancing traction will depend upon the hardness of the abrasive, the durability of the abrasive's bond to the coating, and the quantity and distribution of the abrasive on the coated walkway. There can also be a tendency for the abrasive particles to fill in the low spots of surface roughness, rather than protruding enough to provide effective traction-enhancing asperities.

- Finishes may oxidize, harden, crack, or break up over time, changing both the local slip resistance and the expectable consistency of measurements across a larger area. With loose surfaces, variability in the position, size, and shape of finish fragments under the tribometer's testfoot can affect the reliability of the measurements.

Depending upon the walkway surface, the testfoot material may be roughened or polished by the walkway surface during slips, potentially affecting measurement values. The pre-testing preparation specified for some testfoot materials includes sanding or other resurfacing, though this may not be deemed necessary during wet testing.

\section{Slopes and ramps}

A common method for introducing the concept of "coefficient of friction" involves a sliding block on a surface. Indeed the representation of the threshold value for $\mathrm{COF} / \mathrm{slip}$ resistance can be seen as a vector relationship as shown in Figure 5. Other common friction problems in physics classes involve a block on a ramp, as shown in Figure 6.

These concepts are effective at illustrating why slopes and ramps affect walkway traction. From a physics perspective, all slopes will have a different effective level of traction than if the walkway surfaces were level - assuming a consistent angle of incidence of the foot (or testfoot). As documented in Redfern $^{22}$, required coefficient of friction (RCOF) increases as a function of the tangent of the downslope angle, due to the increase in shear forces on the slope. 


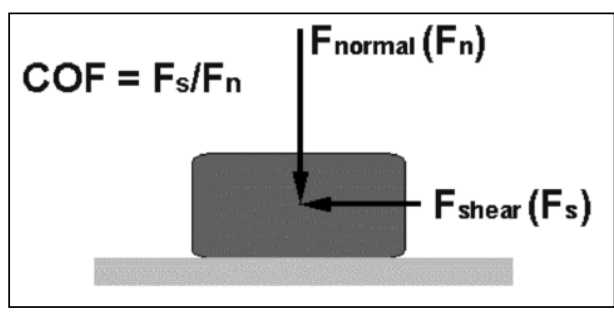

Figure 5

horizontal walkway friction

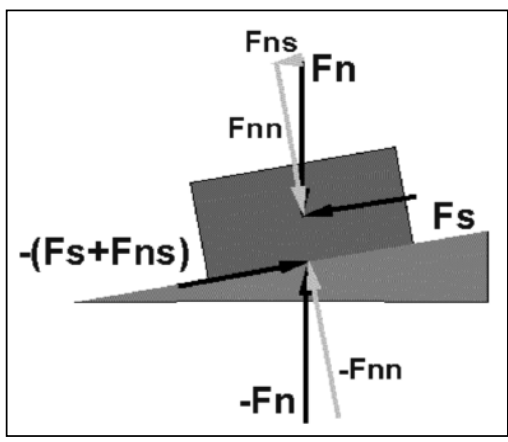

Figure 6 ramp friction

Slopes will be particularly susceptible to directional wear, due to these increased shearing forces - another reason why testing in the direction of pedestrian travel should be considered. Slope falls typically occur on downslopes, and there are differences in pedestrian gait when descending slopes ${ }^{23}$.

- Issues with tribometer testing on slopes

- Tribometers may not be capable of accurate readings on significant slopes, due to various design attributes. The Brungraber Mark II operational procedure in ASTM F1677-05 ${ }^{24}$ (withdrawn) specifies that slope testing can be conducted uphill or cross-slope, but the 10 pound actuating weight on this tribometer will have a varying effect on the testfoot contact pressure, depending upon the slope angle. The Brungraber Mark III, which uses a spring rather than the 10 pound weight, is less susceptible to this issue.

- As most slope falls occur downhill, a tribometer that can measure downhill may provide more relevant measurements. The "articulated strut" features of the English XL (the pneumatic cylinder) and the Brungraber Mark II and Mark III (the strut) will become misaligned at certain ranges of mast angle when the device is operated downhill, but use of proper procedures can support downhill testing.

- The English XL and Brungraber Mark II and Mark III variable-angle tribometers all have a mechanical configuration that uses (for the marked slip resistance reading) the tangent of the angle between the testfoot incidence direction and a vertical plane. Recalling Redfern's comments that traction demand increases on slopes as a function of the slope tangent value, and discounting (for discussion) the effects of gravity on the moving structures of the tribometer (which may be considerable [Li 2009]), it can be seen that a simple slope "correction" may be reasonably performed, based purely on geometry. Templer ${ }^{25}$ describes an equivalent threshold method that appears to rely on this geometric simplicity. 
Copyright (? National Academy of Forensic Engineers (NAFE) http://www.nafe.org. Redistribution or resale is illegal.

Originally published in the Journal of the NAFE volume indicated on the cover page. ISSN: 2379-3252

Restating this method, which is described for downslope measurement, the testfoot incidence angle corresponding to the chosen "safe" threshold is added to the angle of the subject slope from horizontal, and the tangent value of this sum is the minimum "equivalent" measurement that should be obtained for a reasonably slip resistant sloped surface. Though gravity and design issues may affect the ability to directly use this approach for all tribometers, the concept may provide a useful perspective.

- For tribometers that can measure on slopes, and particularly for minor slopes, the effects may not be discernable within the expected variability of the tribometer's measurements. This is discussed in ASSE TRA1264.3-2007 ${ }^{26}$, which reports various effects of slope (using an English $\mathrm{XL}$ ), depending upon the walkway surface.

\section{Bathing surfaces}

Traction testing of shower stalls and bathtubs brings a number of unique considerations - for the purposes of discussion, the term "bathtub" also refers to a shower stall floor. Many bathtub manufacturers offer "non skid" surfaces in addition to bathtubs without "non skid" features. The non-skid features range from specific patterns of texture, to a simple variation in glazing of certain areas. There are two main types of bathtubs - porcelain-coated metal, and plastic/composite.

- Porcelain-coated metal bathtubs: These bathtubs are typically advertised as complying with ASME A112.19.1 ${ }^{27}$; such compliance is required for Federal housing and may be required by local codes. The ASME standard in turn references the aforementioned ASTM F462 ${ }^{28}$ standard, further discussed below. The scopes of the ASME A112.19 standards refer to manufacture, distribution and purchase of new tubs, and do not refer to field tests of existing tubs.

- Plastic/composite bathtubs: These bathtubs are typically advertised as complying with ANSI/IAPMO Z124.1.2 ${ }^{29}$, which also is required for bathtubs in Federal housing. This standard formerly (prior to the current 2005 revision) required compliance with ASTM F462 (discussed below), but such compliance is no longer required. As such, there are no current requirements for the performance of slip resistant features in plastic/composite bathtubs.

\section{- The ASTM F462 test}

- As mentioned, ASTM F462 prescribes the use of the Brungraber Mark I, in about one inch of soapy water. The Mark I is of a design that will experience testfoot adhesion, and the threshold "passing" test value of 0.04 may suggest that this testing isn't directly relevant to humans. The testfoot material for this standard was Dow Corning Silastic 382, a silicone rubber (no longer in production) thought to be similar to human skin, though no direct correlation was established. 
Copyright @ National Academy of Forensic Engineers (NAFE) http://www.nafe.org. Redistribution or resale is illegal Originally published in the Journal of the NAFE volume indicated on the cover page. ISSN: 2379-3252

- This 0.04 "pass" value represents only about $10 \%$ of the typical minimum required pedestrian traction, and represents a value just barely beyond the 0.02 measurement value (on a Mark I) that effectively corresponds to "zero" traction and the lower limit of the tribometer's measurement capability - on a measurement scale that goes to 1.00 . Further, the 0.04 value was chosen as a target "pass" value in the mid 1970's by the initial F462 standard committee, because it could be achieved by $95 \%$ of the tested bathtubs in production at the time ${ }^{30}$. In other words, the 0.04 value is barely measurable and was not chosen based on human propensity for slipping; it was based on manufacturer capability.

Among the additional factors ${ }^{31}$ that complicate bath surface testing are that bathers don't use full stride steps, don't achieve significant walking velocity, and don't use footwear - let alone footwear made of typical testfoot materials. These issues may be relevant when using a tribometer designed for testing "normal" pedestrian walkways.

\section{Contaminants}

Water is the most commonly tested "contaminant" in traction testing. When a puddle of liquid exists on the testing surface, hydroplaning or the "squeeze film" effect may influence testing measurements. Discussions by Chang (2001b) may be informative. This condition will affect some testfoot designs more than others.

- Issues regarding contaminants

- Softer finishes and tested contaminants that accumulate on the testfoot may provide varied test results depending upon the amount of accumulation.

- The fragmentary or granular nature of solid contaminants, such as sand, gravel, oil-dry granules, broken glass, peanut shells, ice-melting compounds, and others, may affect the ability to reliably test affected walkway surfaces. Based upon the typical testfoot design discussed earlier, compliance of the testfoot friction material around movable solid contaminant particles may not be particularly comparable to the compliance of typical footwear around the

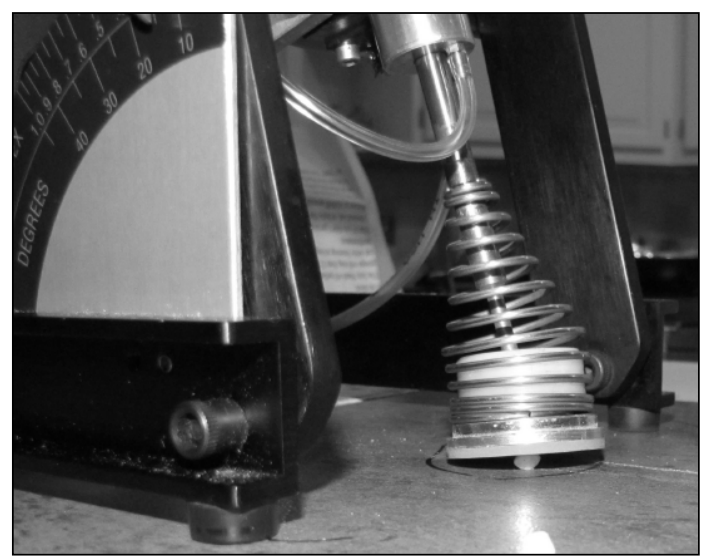

Figure 7

testfoot on salt crystal 
Copyright () National Academy of Forensic Engineers (NAFE) http://www.nafe.org. Redistribution or resale is illegal.

Originally published in the Journal of the NAFE volume indicated on the cover page. ISSN: 2379-3252

same solid particles. The discussion of "draping" in Chang (2001b) may be informative. Similarly, the contact pressure caused by a pedestrian is typically higher than the contact pressure ${ }^{32}$ caused by a tribometer, and expectable (for a pedestrian) crushing of softer fragments may not occur with a tribometer. For larger fragments, again depending upon the testfoot design, the position of the fragment under the testfoot may also affect test results. See Figure 7 showing edge-only contact of an English XL testfoot on a surface in the presence of one ice-melting salt crystal.

\section{Footwear testing}

Some tribometers can be used for testing of footwear material samples. However, comparison of the structure of various shoes will reveal significant differences in the thickness of tread blocks and thickness of sole substrates, which may affect compliance of the sample to the test surface - and the resulting measurement readings. Additionally, many heel designs have a band of solid material around the perimeter, which (considering heel-strike slips) will exhibit different compliance than the adjacent tread blocks.

\section{Traction testing research}

Numerous pedestrian traction research studies have been referenced in this paper; this is only a small sampling of the dozens of potentially relevant papers that may be of interest to the engineer. Literature (e.g. Redfern 1997 and $2001^{33}$, $\mathrm{Li} 2006^{34}$ ) that discusses "required coefficient of friction" and "utilized coefficient of friction" may provide information relevant to an understanding of the insignificance of the commonly-referenced 0.50 threshold traction value. There is, however, a new emphasis on establishing a more robust foundation for determining "safe" traction levels using different tribometers, as discussed below.

As traction testing devices provide (at best) mechanical simplifications of pedestrian falls, appropriate human subject testing is necessary to establish whether the devices can correctly characterize walkway surfaces as reasonably slip resistant - or as unreasonably slippery. This is particularly critical, as much controversy surrounds the fact that different "competent" tribometer designs will measure different traction values for the same surface ${ }^{35}$. Multi-tribometer studies by Powers et al (2010) utilized multi-subject human subject testing on selected reference surfaces. The study served to characterize four reference surfaces (ceramic tile, porcelain, vinyl composition tile, and black polished granite) as increasingly slippery, using a total of 80 test subjects. Different tribometers were then used on the reference surfaces, and the "valid" tribometers were the ones able to both rank the surfaces in order of increasing traction, and to statistically differentiate between the reference surfaces. 
Ultimately, given these reference surfaces, whether a "valid" tribometer finds the threshold of traction safety to correlate to a reading of 0.5 , or 0.0098 , or 341 , or something else, doesn't really matter; the correct reference surface ranking and statistical discrimination (with proper documentation) is the important issue. Given this research and new opportunity for human-based validation of tribometers, future opportunities may exist to include "reliable" traction thresholds in codes and standards, and to justify (for validated tribometers) the expectable differences in their measurements of the same surface.

Apart from this discussion, it is worth recalling that pedestrian fall events involve humans. Traction testing involves consideration of a multitude of extrinsic issues. The intrinsic issues pertaining to the pedestrian, including fall kinematics, expected (and unexpected) injuries, medical conditions, medications - as well as plaintiff/witness statements and depositions, may be at least as relevant in a particular case.

\section{Conclusions}

Traction testing has many complexities that cannot be robustly accommodated by a simplistic binary slippery/not slippery determination. There are no laws, codes, or standards that provide "the recipe" for reliable analyses across all likely scenarios.

The use of a tribometer is only part of a robust analysis. The engineer must have an understanding of the limitations of the tribometer, and of the limited ability to test certain surfaces and contaminants. The engineer's opinions should be informed by awareness of relevant research, particularly research that facilitates the necessary correlation of tribometer test measurements to actual human fall experiences.

\section{Special thanks to:}

Robert J. Brungraber, PhD, PE

James Flynn, PE

Michael L. Romansky, PhD, JD 
Copyright @ National Academy of Forensic Engineers (NAFE) http://www.nafe.org. Redistribution or resale is illegal. Originally published in the Journal of the NAFE volume indicated on the cover page. ISSN: 2379-3252

\section{References}

1. ASTM F1646-05e1, Standard Terminology Relating to Safety and Traction for Footwear. ASTM International, West Conshohocken PA, 2005.

2. ANSI/ICC A117.1-2003, Accessible and Usable Buildings and Facilities. International Code Council, Washington DC, 2003.

3. Brungraber R. An overview of floor slip-resistance research with annotated bibliography. National Bureau of Standards Technical Note 895, 1976.

4. ASTM C1028-07, Standard Test Method for Determining the Static Coefficient of Friction of Ceramic Tile and Other Like Surfaces by the Horizontal Dynamometer Pull-Meter Method. ASTM International, West Conshohocken PA, 2007.

5. Regan Scientific Instruments, Southlake TX.

6. ANSI/NFSI B101.1, Test Method for Measuring Wet SCOF of Common Hard-Surface Floor Materials. National Floor Safety Institute, Southlake TX, 2009.

7. American Slip Meter, Inc., Venice FL

8. ASTM F1678-96 (Withdrawn), Standard Test Method for Using a Portable Articulated Strut Slip Tester (PAST). ASTM International, West Conshohocken PA, 1996.

9. ASTM F462-79r07, Standard Consumer Safety Specification for Slip-Resistant Bathing Facilities. ASTM International, West Conshohocken PA, 2007.

10. Slip-Test Inc., Atlanta GA

11. ASTM F1677-05 (Withdrawn) Standard Test Method for Using a Portable Inclineable Articulated Strut Slip Tester (PIAST) ASTM International, West Conshohocken PA, 2005.

12. Li KW et al. Evaluation of two models of a slipmeter. Safety Science 47 (2009) 1434-1439.

13. Excel Tribometers LLC, Lyman SC

14. ASTM F1679-04 (Withdrawn) Standard Test Method for Using a Variable Incidence Tribometer (VIT). ASTM International, West Conshohocken PA, 2004.

15. Slip-Test, Inc., Atlanta GA

16. ANSI/ASSE Technical Report TR-A1264.3-2007, Using Variable Angle Tribometers (VAT) for Measurement of the Slip Resistance of Walkway Surfaces. American Society of Safety Engineers, Des Plaines IL, 2007.

17. Powers CM et al. Validation of Walkway Tribometers: Establishing a Reference Standard. Journal of Forensic Sciences, March 2010, Volume 55, Number 2 
Copyright $\odot$ National Academy of Forensic Engineers (NAFE) http://www.nafe.org. Redistribution or resale is illegal. Originally published in the Journal of the NAFE volume indicated on the cover page. ISSN: 2379-3252

18. Personal correspondence with Robert Brungraber, PhD, PE, in 2010.

19. Chang WR et al. The role of surface roughness in the measurement of slipperiness. Ergonomics, 2001, Volume 44, Number 13, pp. 1200 - 1216. (Chang 2001a)

20. Chang WR et al. The role of friction in the measurement of slipperiness, Part 1: Friction mechanisms and definition of test conditions. Ergonomics, 2001, Volume 44, Number 13, pp. 1217 - 1232. (Chang 2001b)

21. ASTM D2047 - 04, Standard Test Method for Static Coefficient of Friction of Polish-Coated Flooring Surfaces as Measured by the James Machine. ASTM International, West Conshohocken PA, 2004.

22. Redfern MS, DiPasquale J. Biomechanics of descending ramps. Gait \& Posture 6 (1997), Elsevier Science BV, pp. 119-125.

23. Ibid.

24. ASTM F1677-05 (Withdrawn) Standard Test Method for Using a Portable Inclineable Articulated Strut Slip Tester (PIAST). ASTM International, West Conshohocken PA, 2005.

25. Templer, J. The Staircase: Studies of Hazards, Falls, and Safer Design. MIT Press, 1995, section 3.5.

26. ANSI/ASSE Technical Report TR-A1264.3-2007, Using Variable Angle Tribometers (VAT) for Measurement of the Slip Resistance of Walkway Surfaces. American Society of Safety Engineers, Des Plaines IL, 2007.

27. ASME A112.19.1-2008, Enamelled Cast Iron and Enamelled Steel Plumbing Fixtures. American Society of Mechanical Engineers, New York NY, 2008.

28. ASTM F462-79r07, Standard Consumer Safety Specification for Slip-Resistant Bathing Facilities. ASTM International, West Conshohocken PA, 2007.

29. ANSI/IAPMO Z124.1.2-2005, American National Standard for Plastic Bathtub and Shower Units. International Association of Plumbing and Mechanical Officials, Ontario CA, 2005.

30. Personal correspondence with Robert Brungraber, PhD, PE, in 2010.

31. Besser M et al. Barefoot-Pedestrian Tribometry: In Vivo Method of Measurement of Available Friction between the Human Heel and the Walkway. Industrial Health 2008, 46, 51-58.

32. Chang WR et al. The role of friction in the measurement of slipperiness, Part 2: Survey of friction measurement devices. Ergonomics, 2001, Volume 44, Number 13, pp. 1233 - 1261. (Chang 2001c)

33. Redfern $M$ et al. Biomechanics of slips. Ergonomics, 2001, Vol. 44, No. 13, 1138-1166. 
Copyright $\odot$ National Academy of Forensic Engineers (NAFE) http://www.nafe.org. Redistribution or resale is illegal.

Originally published in the Journal of the NAFE volume indicated on the cover page. ISSN: 2379-3252

34. Li KW et al. Relationship between the measured friction coefficients of floors on a horizontal surface and on a 10 degree ramp. International Journal of Industrial Ergonomics 36 (2006), 705-711.

35. Chang WR, Matz $S$. The slip resistance of common footwear materials measured with two slipmeters. Applied Ergonomics 32 (2001) 549-558. (Chang 2001d) 


\section{Forensic Engineering \\ Use of Walkway Traction Testing}

by John Leffler, P.E. (NAFE 709M)

\section{Author's correction:}

On page 133, first paragraph, it states "Further, the 0.04 value was chosen as a target 'pass' value in the mid 1970's by the initial F462 standard committee, because it could be achieved by $95 \%$ of the tested bathtubs in production at the time ${ }^{30 "}$. This was based on conversations with Dr. Robert J. Brungraber, PE.

In fact, however, the 0.04 value was chosen to exclude (with a safety factor of 2) all non-textured bathing surfaces traction-tested in a comparative study of 50 different bathing surfaces.

Reference: Brungraber RJ, Adler SC. Technical support for a slip-resistance standard. In: Anderson C, Senne J editors. Walkway surfaces: measurement of slip resistance, ASTM STP 649. Philadelphia; American Society for Testing and Materials: 1978. 